Kohjiro Furuya MD, Rejju Shimizu MD,

Yoshihiro Hirabayashi MD, Royosuke Ishii MD, Hirokazu Fukuda MD

\title{
Stress hormone
} responses to major intra-abdominal surgery during and immediately after sevoflurane-nitrous oxide anaesthesia in elderly patients

We studied the responses of plasma epinephrine, norepinephrine, adrenocorticotropic hormone (ACTH), cortisol, and antidiuretic hormone $(A D H)$ during and immediately after sevoflurane-nitrous oxide anaesthesia supplemented with vecuronium in seven elderly patients (mean $76.6 \pm 1.7$ SEM) who underwent major intra-abdominal surgery. The plasma concentrations of norepinephrine, $A C T H$, cortisol, and $A D H$ increased in response to surgical procedures $(P<0.05)$. The plasma concentration of $A D H$ increased to a peak concentration of $189.1 \pm 20.7 \mathrm{pg} \cdot \mathrm{ml}^{-1} 30 \mathrm{~min}$ after skin incision $(P$ $<0.05$ ). the plasma concentrations of epinephrine, norepinephrine, $A C T H$, and cortisol increased to peak concentrations of $408.6 \pm 135.5 \mathrm{pg} \cdot \mathrm{ml}^{-1}, 635.7 \pm 167.8 \mathrm{pg} \cdot \mathrm{ml}^{-1}, 222.6 \pm 48.0$ $\mathrm{pg} \cdot \mathrm{ml}^{-1}$, and $113.6 \pm 67.5 \mu \mathrm{g} \cdot \mathrm{dl}^{-1}$, respectively immediately after tracheal extubation $(P<0.05)$. We conclude that, in the elderly patients, the responses of stress hormones to major intraabdominal surgery were preserved during sevoflurane-nitrous

\section{Key words}

ANAESTHESIA: geriatric;

ANAESTHETICS, VOLATILE: Sevoflurane;

HORMONES: adrenocorticotropic, antidiuretic, catecholamines, corticosteroids.

From the Department of Anesthesiology, Jichi Medical School, Tochigi, Japan.

Address correspondence to: Dr. K. Furuya, Department of Anesthesiology, Jichi Medical School, Minamikawachi-machi, Kawachigun, Tochigi-ken, 329-04, Japan. Telephone number 0285-44-2111, FAX number 0285-44-4108.

This work was supported by a grant from the Ministry of Health and Welfare of Japan.

Accepted for publication 8th February, 1993. oxide anaesthesia sufficient to prevent increases in arterial pressure and heart rate. The strongest responses of epinephrine, norepinephrine, ACTH, and cortisol were elicited immediately after treacheal extubation.

Cette étude porte sur les réponses de l'épinéphrine, de la norépinéphrine, de $A C T H$, du cortisol, et de l'ADH pendant et immédiatement après l'anesthésie au sévoflurane-protoxyde d'azote supplémentée par du vécuronium chez sept patients avancés en âge (moyenne 76,6 $\pm 1,7$ SEM) opérés pour une chirurgie viscérale majeure. Les concentrations plasmatiques de norépinéphrine, d'ACTH, de cortisol, et d'ADH augmentent en réponse à la chirurgie $(P<0,05)$. La concentration plasmatique d'ADH atteint un maximum de $189,1 \pm 20,7 \mathrm{pg} \cdot \mathrm{ml}^{-1}$ après lincision $(P<0,05)$. La concentration plasmatique de l'épinéphrine, de la norépinéphrine, de l'ACTH et du cortisol atteignent respectivement un maximum de 408,6 $\pm 135,5$ $\mathrm{pg} \cdot \mathrm{dl}^{-1}, 635,7 \pm 167,8 \mathrm{pg} \cdot \mathrm{ml}^{-1}, 222,6 \pm 48,0 \mathrm{pg} \cdot \mathrm{ml}^{-1}, \mathrm{et}$ de 113,6 $\pm 67,5 \mu \mathrm{g} \cdot \mathrm{dl}^{-1}$ immédiatement après l'intubation $(P$ $<0,05)$. En conclusion, la réponse des hormones de stress à une chirurgie viscérale majeur chez le sujet âgé est conservées pendant une anesthésie au sévoflurane-protoxyde d'azote suffisamment profonde pour prévenir une montée de la pression artérielle et de la fréquence cardiaque. Les réponses les plus intenses de l'épinéphrine, de la norépinéphrine, de l'ACTH et du cortisol sont survenues immédiatement après lintubation de la trachée.

Although there is a functional decline in most vital organs and consequent loss of organic reserve with increasing age, no change in adrenocortical function could be demonstrated with advancing age in response to ACTH stimulation in the elderly ranging between 60 and $96 \mathrm{yr}^{1}{ }^{1}$ 
and the adrenocorticol response to major surgery and anaesthesia is found to be well preserved in elderly patients. ${ }^{2}$ However, the responses of stress hormones such as epinephrine, norepinephrine, adrenocorticotropic hormone $(\mathrm{ACTH})$, and antidiuretic hormone $(\mathrm{ADH})$ to major intra-abdominal surgery during sevoflurane-nitrous oxide anaesthesia remain unknown in elderly patients.

Sevoflurane, a new inhaled anaesthetic agent, provides rapid anaesthetic induction and recovery consistent with its low blood solubility (a blood/gas partition coefficient of 0.60$)^{3}$ and rapidly and easily controllable anaesthetic depth. In addition, it has many advantages associated with the characteristics of an ideal inhaled anaesthetic. ${ }^{4}$

We investigated, in terms of circulating stress hormones, how elderly patients respond to major intraabdominal surgery during and immediately after sevoflurane-nitrous oxide anaesthesia.

\section{Methods}

Seven patients (five men and two women, mean $76.6 \pm$ 1.7 SEM yr) scheduled to undergo major intra-abdominal surgery were studied. All patients were in ASA class II. The profiles of the patients are shown in Table I. They did not have severe physiological or psychological disorders such as malnutrition, depression, or senile dementia. None of them had apparent endocrine, metabolic, renal, and haepatic diseases. Informed consent to perform the study was obtained at the time of the preoperative visit and the study was approved by our institutional human investigation committee. All the patients received premedication with atropine sulfate $0.3 \mathrm{mg}$ and hydroxyzine $12.5 \mathrm{mg}$ im one hour before induction of anaesthesia. On arrival in the operating room, the radial artery was cannulated under local anaesthesia for monitoring arterial pressure and drawing blood samples. An epidural catheter was inserted through the middle thoracic interspace $\left(T_{7}-T_{8}\right)$ for postoperative pain relief. No local anaesthetics were administered epidurally throughout the anaesthetic course.

Anaesthesia was induced by stepwise increases in sevoflurane concentration from $1 \%$ to $4 \%$ in $70 \%$ nitrous oxide until eyelash reflex disappeared. The trachea was intubated after the administration of vecuronium $0.15 \cdot \mathrm{mg} \cdot \mathrm{kg}^{-1}$ iv Ventilation was controlled with a volume-cycled ventilator to maintain adequate $\mathrm{PETCO}_{2}$ ( 35 to $40 \mathrm{mmHg}$ ). Vecuronium was administered intermittently during the surgical procedures to provide optimal surgical conditions. The concentration of sevoflurane was varied from $1.5 \%$ to $3 \%$ in $70 \%$ nitrous oxide to maintain optimal anaesthetic depth judged by changes in arterial pressure and heart rate throughout the surgical and anaesthetic course. After the end of surgery, residual neuromuscular blockade was reversed with atropine sul-
TABLE I Patients' profiles

\begin{tabular}{|c|c|c|c|c|}
\hline Patient & $\operatorname{Sex}$ & $\begin{array}{l}\text { Age } \\
(y r)\end{array}$ & $\begin{array}{l}\text { Weight } \\
(\mathrm{kg})\end{array}$ & Operation \\
\hline 1 & Woman & 83 & 47 & Hemicolectomy \\
\hline 2 & Man & 71 & 45 & $\begin{array}{l}\text { Sigmoidectomy and total } \\
\text { cystectomy }\end{array}$ \\
\hline 3 & Woman & 72 & 53 & Total gastrectomy \\
\hline 4 & Man & 74 & 52 & $\begin{array}{l}\text { Total gastrectomy and } \\
\text { cholecystectomy }\end{array}$ \\
\hline 5 & Man & 77 & 43 & Subtotal gastrectomy \\
\hline 6 & Man & 77 & 53 & Total gastrectomy \\
\hline 7 & Man & 82 & 66 & Subtotal gastrectomy \\
\hline Mean & & 76.6 & 51.3 & \\
\hline SEM & & 1.7 & 2.9 & \\
\hline
\end{tabular}

fate $1.0 \mathrm{mg}$ and neostigmine $2.5 \mathrm{mg} \dot{i}$, followed by discontinuation of sevoflurane and nitrous oxide, and 100\% oxygen was administered. The trachea was extubated after the patient responded to a simple verbal command. After the last blood sample was drawn, the patient was transferred to the recovery room and a local anaesthetic was administered through the epidural catheter for postoperative pain relief.

Plasma was separated at $4^{\circ} \mathrm{C}$ and then frozen at $-20^{\circ} \mathrm{C}$ until assayed. Plasma epinephrine and norepinephrine concentrations were measured by high-performance liquid chromatography. ${ }^{5}$ The plasma ACTH concentration was deteremined by radioimmunoassay ${ }^{6}$ using the Allegro ACTH Kit (Nihon Med+Physics, Inc., Hyogo, Japan). The plasma cortisol concentration was deteremined by radioimmunoassay ${ }^{7}$ using the Gamma Cortisol Kit (Baxter, Inc., Tokyo, Japan). The plasma ADH concentration was determined by radioimmunoassay ${ }^{8}$ using AVP-RIA Kit (Mitsubishiyuka, Inc., Tokyo, Japan). Reference values for epinephrine, norepinephrine, ACTH, cortisol, and $\mathrm{ADH}$ in unrestrained patients during supine rest in the morning are 0 to $120 \mathrm{pg} \cdot \mathrm{ml}^{-1}, 60$ to $450 \mathrm{pg} \cdot \mathrm{ml}^{-1}$, 30 to $60 \mathrm{pg} \cdot \mathrm{ml}^{-1}, 4.0$ to $18.3 \mu \mathrm{g} \cdot \mathrm{dl}^{-1}$, and 0.3 to 3.5 $\mathrm{pg} \cdot \mathrm{ml}^{-1}$, respectively.

The sampling times for the hormone measurements were: anaesthetic induction (\#1), within one minute before tracheal intubation (\#2), within one minute after tracheal intubation (\#3), immediately before skin incision (\#4), 30 min after skin incision (\#5), when active intra-abdominal surgical procedures were being performed, $60 \mathrm{~min}$ after skin incision ( $\# 6)$, within one minute after tracheal extubation (\#7), when all anaesthetic agents were discontinued.

The data were presented as mean \pm SEM. The nonparametric Wilcoxon signed-rank test was used to compare values within group. All statistical analyses were car- 
TABLE II Haemodynamic and hormonal data

\begin{tabular}{|c|c|c|c|c|c|c|c|}
\hline $\begin{array}{l}\text { Sampling } \\
\text { time }\end{array}$ & $\begin{array}{l}M A P \\
(m m H g)\end{array}$ & $\begin{array}{l}H R \\
\left(\text { Beat } \text { min }^{-1}\right)\end{array}$ & $\begin{array}{l}\text { Epinephrine } \\
\left(\mathrm{pg} \cdot \mathrm{m}^{-}\right)\end{array}$ & $\begin{array}{l}\text { Norepinephrine } \\
\left(\mathrm{og} \cdot \mathrm{m}^{-1}\right)\end{array}$ & $\begin{array}{l}A C T H \\
\left(p g \cdot m t^{\prime}\right)\end{array}$ & $\begin{array}{l}\text { Cortisol } \\
\left(\mu g \cdot d l^{-1}\right)\end{array}$ & $\begin{array}{l}A D H \\
\left(p g \cdot m^{-1}\right)\end{array}$ \\
\hline 1 & $102,3 \pm 6.3$ & $77.7 \pm 4.6$ & $67.1=24.9$ & $165.7 \pm 42.3$ & $51.7 \pm 4.1$ & $12.7 \pm[.0$ & $1.1 \pm 0.2$ \\
\hline 2 & $71.4 \pm 7.7^{*}$ & $72.9 \pm 6.3$ & $18.6 \pm 6.3^{*}$ & $235.7 \pm 62.9^{*}$ & $\$ 3.1 \pm 5.6$ & $11.6 \pm 1.1$ & $6.2 \pm 4.7$ \\
\hline 3 & $89.9 \pm 8.2$ & 95.1 $17.2^{*}$ & $15.7 \pm 6.5^{*}$ & $350.0 \pm 70.9^{*}$ & $51.9 \pm 5.8$ & $11.8 \pm 1.2$ & $5.0 \pm 3.6^{*}$ \\
\hline 4 & $64.4 \pm 6.7^{*}$ & $71.7 \pm 5.5^{*}$ & $8.6 \pm 3.4^{*}$ & $207.1 \pm 50.5$ & $45.5 \pm 4.6$ & $11.2 \pm 1.3$ & $1.4 \pm 0.4$ \\
\hline 5 & $77.3 \pm 3.2^{*}$ & $76.0 \pm 4.1$ & $111,4 \pm 24,0$ & $411.4 \pm 57.0^{*}$ & $131.7 \pm 18.6^{*}$ & $17.9 \pm 0.8^{*}$ & $189.1 \pm 20.7^{*}$ \\
\hline 6 & $81.7 \pm 2.6^{*}$ & $78.9 \pm 5.1$ & $104.3 \pm 27.4$ & $448.6 \pm 76.0^{*}$ & $150.1 \pm 20.7^{*}$ & $19.7 \pm 0.7^{*}$ & $167.4 \pm 34.6^{*}$ \\
\hline 7 & $107.6 \pm 4.9$ & $83.6 \pm 8.5$ & $408.6 \pm 135.5^{*}$ & $635.7 \pm 167.8^{*}$ & $222.6 \pm 48.0^{*}$ & $113.6 \pm 67.5^{*}$ & $127.3 \pm 19.2^{*}$ \\
\hline
\end{tabular}

MAP, mean arterial pressure; HR, heart rate; ACTH, adrenocorticotropic hormone; $\mathrm{ADH}$, antidiuretic hormone; sampling time 1 , before placement of an epidural catheter and anaesthetic induction; 2 , before tracheal intubation; 3, immediately after tracheal intubation; 4 , before skin incision; 5 , 30 min after skin incision; 6, 60 min after skin incision; 7, within one minute after tracheal extubation.

$* P<0.05$ compared with sampling time $\mathbf{I}$.
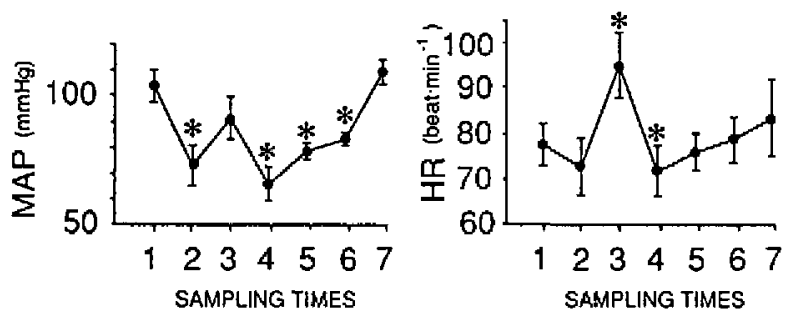

FIGURE 1 Changes in mean arterial pressure and heart rate (mean \pm SEM). ${ }^{*}$ Denotes $P<0.05$, compared with sampling time 1 .

Sampling time 1 represents control values before placement of an epidural catheter and anaesthetic induction. Sampling time 2 and 3 reprcsents values before and immediately after tracheal intubation, respectively. Sampling time 4 represents values before skin incision. Sampling time 5 and 6 represent values at 30 and 60 min after skin incision, respectively. Sampling time 7 represents values immediately after tracheal extubation.

ried out using STATVIEW SE+GRAPHICS ${ }^{\circledR}$ software (Abacus Concept, Inc., version 1.04, 1991). A $P$ value $<0.05$ was considered statistically significant.

\section{Results}

Haemodynamic and hormonal data in the seven patients are shown in Table II. Mean arterial pressure (MAP) decreased before tracheal intubation, before skin incision, and during surgical procedures $(P<0.05$ vs sampling time 1). Heart rate increased only immediately after tracheal intubation $(P<0.05$ ). After tracheal extubation mean arterial pressure and heart rate did not differ from control (Figure 1). Changes in plasma concentrations of epinephrine and norepinephrine were within the normal range during anaesthetic induction and surgical procedures (Figure 2). The plasma concentrations of ACTH and cortisol did not change during anaesthetic induction, but increased $30 \mathrm{~min}$ and $60 \mathrm{~min}$ after skin incision $(P$

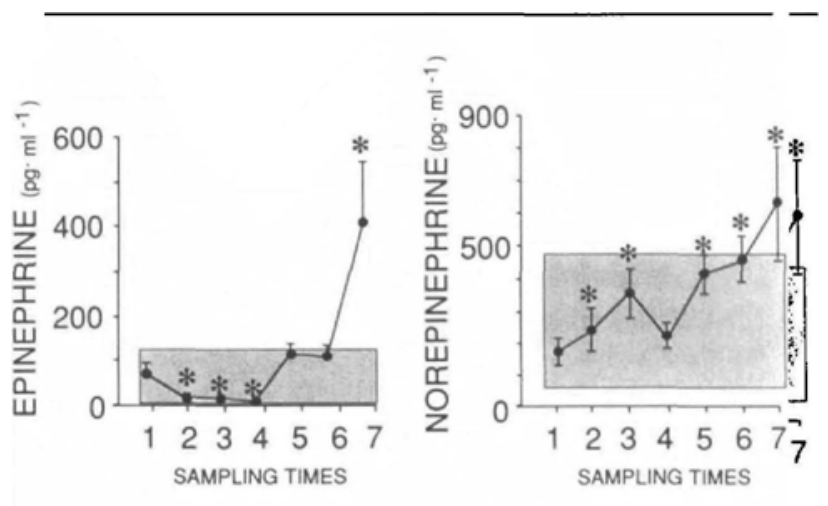

FIGURE 2 Changes in plasma concentrations of epinephrine and norepinephrine. See legend in Figure 1 for identification of symbols. The shaded areas represent the normal range of each hormone.

$<0.05$ ) (Figure 3). The plasma cortisol concentrations immediately after tracheal extubation varied from patient to patient over a wide range from $21.6 \mu \mathrm{g} \cdot \mathrm{dl}^{-1}$ to 502 $\mu \mathrm{g} \cdot \mathrm{dl}^{-1}$ over the normal range. The plasma concentration of $\mathrm{ADH}$ increased from $1.1 \pm 0.2 \mathrm{pg} \cdot \mathrm{ml}^{-1}$ before anaesthetic induction (sampling time 1) to $189.1 \pm 20.7$ $\mathrm{pg} \cdot \mathrm{ml}^{-1} 30 \mathrm{~min}$ after skin incision $(P<0.05)$ and thereafter remained at higher concentrations than preanaesthetic value (Figure 4). Immediately after tracheal extubation, the plasma concentrations of epinephrine, norepinephrine, ACTH, and cortisol increased to peak concentrations of $408.6 \pm 135.5 \mathrm{pg} \cdot \mathrm{ml}^{-1}, 635.7 \pm 167.8$ $\mathrm{pg} \cdot \mathrm{ml}^{-1}, 222.6 \pm 48.0 \mathrm{pg} \cdot \mathrm{ml}^{-1}$, and $113.6 \pm 67.5$ $\mu \mathrm{g} \cdot \mathrm{dl}^{-1}$, respectively $(P<0.05)$ (Figures 2,3 , and 4 ).

\section{Discussion}

Our study demonstrated that elderly patients responded to major intra-abdominal surgical stress during an ade- 


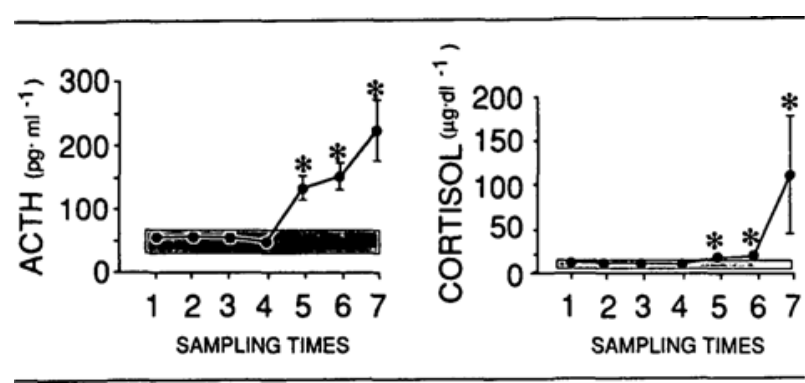

FIGURE 3 Changes in plasma concentrations of ACTH and cortisol. See legend in Figure 1 for identification of symbols.

quate depth of sevoflurane-nitrous oxide anaesthesia and showed the strongest response immediately after tracheal extubation.

Murakawa et al. ${ }^{9}$ evaluated the effects of sevofluranenitrous oxide anaesthesia and surgery on plasma concentrations of epinephrine and norepinephrine in 12 patients aged from 15 to $65 \mathrm{yr}$ who underwent gastrointestinal or gynaecological surgery and found that plasma epinephrine and norepinephrine concentrations increased during and after surgery. The plasma concentrations of epinephrine and norepinephrine were 1.3 to 2.7 times higher in our patients than in their patients before induction of anaesthesia, at $30 \mathrm{~min}$ and $60 \mathrm{~min}$ after skin incision, and after surgery. This suggests that the adreno-medullary glands and the sympathetic nervous system were more strongly activated by surgical procedures and during emergence from anaesthesia in elderly patients than in the younger adult patients. A difference in plasma catecholamine concentrations between young and old healthy males has been reported by Fleg et al. They demonstrated that for any relative level of aerobic stress incurred by healthy men during treadmill exercise, plasma catecholamine concentrations were higher in the elderly. ${ }^{10}$

In our study the plasma concentrations of $\mathrm{ACTH}$ and cortisol were increased by surgical procedures, though their peak values were seen immediately after tracheal extubation. Murakawa et al. " reported that plasma ACTH and cortisol concentrations increased with surgical stimulation and reached peak values during sevofluranenitrous oxide anaesthesia. Bowen $e t$ al. ${ }^{2}$ reported that plasma cortisol concentrations increased in 12 elderly patients aged 74 to $83 \mathrm{yr}$ (mean $79 \mathrm{yr}$ ) who underwent major surgery under halothane anaesthesia. These findings suggest that the pituitary-adrenocortical response to surgical procedures may be well preserved in elderly patients during anaesthesia.

Our findings that the plasma concentrations of epinephrine, norepinephrine, ACTH, and cortisol increased in response to tracheal extubation are in agreement with those of Udelsman et al. ${ }^{12}$ They found that the immediate

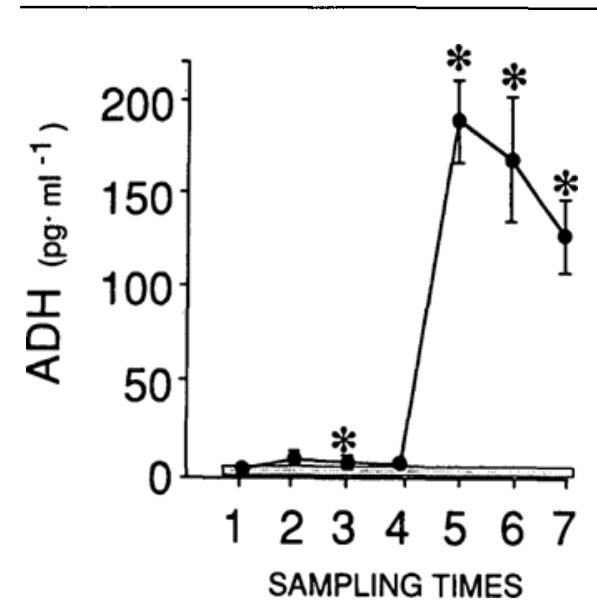

FIGURE 4 Changes in plasma concentrations of ADH. See legend in Figure 1 for identification of symbols.

postoperative period was associated with profound elevations of plasma ACTH, cortisol, and epinephrine concentrations in 11 patients (mean $45 \pm 15 \mathrm{SD}$ yr) after parathyroid or thyroid surgery under isoflurane anaesthesia and concluded that the major determinant of ACTH, cortisol, and epinephrine secretion was anaesthesia reversal and recovery, and not surgical trauma. Our results showed that emergence from anaesthesia in the absence of adequate pain control should elicit the strongest stress response throughout the anaesthetic course in elderly patients as well as in young adult patients examined by Udelsman et al.

The plasma ADH concentration increased by 190 times 30 min after skin incision, compared with the preanaesthetic value, but the act of tracheal extubation was not followed by an increase in the plasma concentration of $\mathrm{ADH}$. This suggests that surgical procedures may release more strongly ADH than tracheal extubation.

Mean arterial pressure and heart rate did not increase during surgical procedures or immediately after tracheal extubation in spite of considerable increases in plasma catecholamines. The fact that cardiovascular adrenergic receptor sensitivity to agonists decreases with aging may explain the reduced responsiveness of the cardiovascular system to increased stress hormones acting on the autonomic nervous system. ${ }^{13}$ This indicates that haemodynamic changes are not sensitive indicators of change in stress hormones.

Since plasma concentrations of stress hormones represent the integration of production, release, degradation, and clearance of stress hormones, certain limitations of using plasma concentrations of stress hormones as an index of stress responses should be recognized. Plasma stress hormones may remain high in elderly patients 
whose diminished haepatic function may slow down clearance of plasma stress hormones. Increased plasma stress hormones may exert metabolic effects that include hyperglycaemia, increased protein catabolism, and sodium and water retention, but no data are available on the effects of stress hormones on the metabolic resonses to anaesthesia and surgical procedures in elderly patients.

Further studies are needed to examine the pharmacokinetic, pharmaco-dynamic, and metabolic effects of stress hormones during and immediately after sevofluranenitrous oxide anaesthesia in elderly patients.

In conclusion, we confirmed that the responses of stress hormones in elderly patients of $70 \mathrm{yr}$ and above were preserved during surgical procedures under sevofluranenitrous oxide anaesthesia and that tracheal extubation elicited the strongest responses of stress hormones throughout the course of anaesthesia.

\section{References}

1 West CD, Brown H, Simons EL, Carter DB, Kumagai LF, Englert $E$. Adrenocortical function and cortisol metabolism in old age. J Clin Endocrinol Metab 1961; 21: 1197-207.

2 Bowen DJ, Richardson DJ. Adrenocortical response to major surgery and anaesthesia in elderly patients. Br J Anaesth 1974; 46: 873-6.

3 Wallin RF, Regan BM, Napoli MD, Stern IJ. Sevoflurane: a new inhalational anesthetic agent. Anesth Analg 1975; 54: 758-66.

4 Eger EI. Current status of sevoflurane and desflurane. 1992 Review course lectures, supplement to Anesthesia and Analgesia. 1992: 81-5.

5 Hjemdahl P, Daleskog $M$, Kahan T. Determination of plasma catecholamines by high performance liquid chromatography with electrochemical detection: comparison with a radioenzymatic method. Life Sci 1979; 25: 131-8.

6 Chrousos GP, Schulte HM, Oldfield EH, Gold PW, Cutler $G B$, Loriaux $D L$. The corticotropin-releasing factor stimulation test: an aid in the evaluation of patients with Cushing's syndrome. N Engl J Med 1984; 310: 622-6.

7 Kao $M$, Voina $S$, Nichols $A$, Horton $R$. Parallel radioimmunoassay for plasma cortisol and 11-deoxycortisol. Clin Chem 1975; 21: 1644-7.

8 Thibonnier MJ, Marchetti JP, Corvol PL, Menard JE, Milliez $P$. Advantages and drawbacks of AVP radioimmunoassay in plasma and unine of normal subjects. Horm Metab Res 1981; 13: 300-1.

9 Murakawa T, Satoh Y, Kudo T, Kudo M, Matsuki A, Oyama $T$. Effects of sevoflurane anesthesia and surgery on plasma catecholamine levels. Jpn J Anesth 1989; 38: 1456-61.
10 Fleg JL, Tzankoff SP, Lakatta EG. Age-related augmentation of plasma catecholamines during dynamic exercise in healthy males. J Appl Physiol 1985; 59: 1033-9.

11 Murakawa T, Satoh Y, Kudo T, Kudo M, Matsuki A, Oyama $T$. Effects of sevoflurane anesthesia and surgery on anterior pituitary and adrenocortical function in man. Jpn J Anesth 1987; 36: 1058-63.

12 Udelsman R, Norton JA, Jelenich SE, et al. Responses of the hypothalamic-pituitary-adrenal and renin-angiotensin axes and the sympathetic system during controlled surgical and anesthetic stress. J Clin Endocrinol Metab 1987; 64: 986-94.

13 Plein JB, Plein EM. Pharmacokinetics and pharmacodynamics in the geriatric patient. In: Krechel SW (Eds.). Anesthesia and the Geriatric Patient. Orlando: Grune \& Stratton, 1984; 74-98. 